\title{
Outdoor activities, negligence, and the law.
}

\author{
Reviewed by Dr Andrew Brookes
}

\author{
La Trobe University
}

Fullbrook, J. (2005). Outdoor activities, negligence, and the law. Aldershot, Hampshire: Ashgate.

288 pages. ISBN-13 978-0-7546-4235-0

In the preface to 'Outdoor Activities, Negligence, and the Law,' Julian Fulbrook expresses the hope the book, written as legal analysis, will prove useful for organizers of outdoor activities. It is a hope that I think will be fully realized. This is a book that should be in the library of any individual or organization with a serious interest in safety in outdoor activities, especially those involving young people.

Fulbrook is a barrister and Dean of Graduate Studies at the London School of Economics. I will leave any evaluation of the book as a legal review to those better qualified, although I doubt it will lead any aspiring bush lawyers astray. It has been positively reviewed in Common Law World Review (Stanton, 2006). Fulbrook's aim, for the legal reader, is to provide both an analysis of legal cases involving outdoor activities, and to place these in a wider social and historical context. For other readers, Fulbrook's purpose is to demystify the law and counter some of the fears about the law that sometimes seem to threaten the whole enterprise of taking young people into the outdoors. Whether he achieves that purpose will depend on the reader, but my guess is that many readers will find the book both enlightening, and reassuring.

The book is organised into three parts: (1) Providers and Participants, (2) The Legal Principles and (3) Practical Applications. In effect these three parts provide three different approaches to the law and outdoor activities, in some instances examining the same cases from the perspectives of the organization, regulation, and history of outdoor activities, the legal principles that apply, and the safety considerations. I found this approach to be helpful, rather than repetitive; in any case, each of the sections can be read somewhat independently.

Australian readers will find few references to Australian cases, but should find Fulbrook's accounts of both cases and legislation in Great Britain interesting and relevant. He prefaces the book with some discussion about contemporary debates in Great Britain, and begins his analysis with an account of the Lyme Bay disaster and the legislation that led to the establishment of the Adventure Activities Licensing Authority (AALA). Inevitably, details in this discussion will date eventually, but the lessons learned from the history of incidents in the UK and elsewhere will continue to be worth attending to.

The book is not intended to be an original piece of scholarship on either the history of outdoor activities in Great Britain, nor on safety in the outdoors. Although it contributes to both, it should not be used that way. I found myself disagreeing with his safety analysis here and there, but to dwell on that would be to miss the point. Fulbrook's academic focus, and the thread which runs through the whole book, is the law as it applies to outdoor activities. However, aside from the legal analysis, Fulbrook brings together considerable detail about a great many incidents. He is an engaging narrator, and the anecdotes that illustrate every point and nuance make the book readable, informative, and also an important contribution to safety in the outdoors. In my opinion it is important to keep the stories of what has gone amiss in the past in circulation. This is what contributes to a safety culture. Even without the legal analysis, the book is worth reading for the cases described. The outdoor field owes Fulbrook a debt of gratitude for this excellent contribution.

\section{Reference}

Stanton, K. (2006). Book review. Outdoor Activities, Negligence, and the Law by Julian Fulbrook. Common Law World Review, 35, 164-166.

\section{About the reviewer}

Dr. Andrew Brookes teaches and researches in the School of Outdoor Education and Environment, La Trobe University, Bendigo, Australia. In addition to his research on fatal incidents and safety, he has interests in outdoor environmental education, and examining the validity of claimed aims and purposes for outdoor education. He is presently completing a study examining some educational aspects of long term travel in remote Australia by families. Email: a.brookes@latrobe.edu.au 